\title{
Sciendo
}

DOI: $10.1515 /$ sspjce-2020-0015

\section{Methodology of Research on Transparent Wood in Architectural Constructions}

\author{
Viktor Karl'a \\ Technical University of Košice, Slovakia \\ Faculty of Civil Engineering, Institute of Architectural Engineering \\ e-mail: viktor.karla@tuke.sk
}

\begin{abstract}
The article describes methodology of research on transparent wood in architectural constructions which is to be held at Faculty of Civil Engineering at Technical University in Košice. The goal is to set multiple stages of research to be able to obtain samples of transparent wood of different species and to evaluate them and subsequently to design constructions suitable for the properties of the obtained material. The aim is to be for the constructions of façade systems and beams of composite cross-section, possibly with the focus on "I" section beams made of transparent wood, but different approaches will also be considered. First, the designs will be evaluated and adjusted using suitable software and after, they will be built and experimentally tested. As the technology at the university will not allow the production of full scale models, some models in scale shall be produced and evaluated in Košice during the upcoming months.
\end{abstract}

Key words: transparent wood, façade systems, composite cross-section beams, veneers, lignin, cellulose

\section{Introduction}

Transparent wood was first mentioned in the article Transparent Wood - A New Approach in the Functional Study of Wood Structure by German scientist Sigfried Fink in 1992 [1]. In his research he turned wood samples transparent in order to be able to better observe specific three dimensional structures of wood. In his attempt he was inspired by a Spalteholz, who in 1914 introduced a technique to make thick body organs transparent for analytical purposes using organic liquids with appropriate refractive indexes.

Between 2015 and 2016, two teams at Swedish KTH Royal Institution of Technology and at University of Maryland rediscovered Fink's invention and started their research on properties of transparent wood and suggested its possible applications for lightweight low-cost structures in light-transmitting buildings, transparent solar cell windows, furniture, or as structural material in automobiles and optoelectronics [2][3]. While at Maryland, their research of transparent wood is part of their ongoing research of super wood structures, in KTH they 
focus solely on transparent wood, therefore have published more articles related to this content and have come up with interesting innovations considering the concepts of its fabrication and enhancing its properties.

So far, there are some interesting facts discovered about transparent wood and its production has been refined over the couple of years of research, but is still has its limits. Only small samples were created up until this date, but at KTH they are now recruiting more people to work on fabrication of large transparent wood samples.

Research at Technical University in Košice shall be focused on applying the newly discovered composite material in building industry in architectural constructions while considering its limits, advantages and disadvantages. All of the previous research conducted at KTH and Maryland will be considered and incorporated, so it will be possible to best tune the process of fabrication of transparent wood for the intended constructions.

\section{Creation of transparent wood samples}

The first stage of research at TUKE, of course, is to be creation of samples of transparent wood. Multiple veneers of various wood species and thicknesses shall be used for the creation. All of them shall be bought from a local supplier. Species considered are balsa, pine, spruce, birch, maple, ash, lime, walnut, oak and beech which are available in thicknesses of $0.60,0.90,1.40$ and $2.50 \mathrm{~mm}$. During all stages, an environmental product declaration (EPD) will be created, so it will be possible to compare transparent wood structures to those made of glass and thus to finally determine, whether constructions made of transparent wood are in reality more ecological or it is only a misleading presumption.

\subsection{Lignin modification}

To create transparent wood, the first step is to remove or modify lignin. As the lignin modification produces more stable samples, it was chosen as the better method for the purpose. Optical properties are very similar compared to delignification method, although slightly weaker. The great advantage of lignin modification compared to delignification is better ecology, as fewer chemicals are required to produce such samples and these samples also show better mechanical properties [4].

The lignin modification solution shall be prepared using a recipe published by KTH mixing chemicals in the following order: deionized water, sodium silicate $\mathrm{Na}_{2} \mathrm{SiO}_{3}(3.0 \mathrm{wt} \%$ ), sodium hydroxide solution $\mathrm{NaOH}(3.0 \mathrm{wt} \%)$, magnesium sulfate $\mathrm{MgSO}_{4} \quad(0.1 \mathrm{wt} \%)$, diethylenetriaminepentaacetic acid DTPA $(0.1 \mathrm{wt} \%)$, and then hydrogen peroxide $\mathrm{H}_{2} \mathrm{O}_{2}(4.0$ wt \%). The wood substrates will then be submerged in the solution at $70{ }^{\circ} \mathrm{C}$ until the veneers become white. The samples shall then be thoroughly washed with deionized water and kept in water until use [4].

\subsection{Polymer infiltration}

After lignin modification, samples will be ready for polymer infiltration to become transparent. Various kinds of polymers have been used to create transparent wood. At KTH, they mainly used poly (methyl methacrylate) PMMA, while in Maryland, they used epoxy

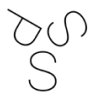


resins. The important factor is the refractive index of polymer, which should be close to a value of 1.61, which is the refractive index of lignin to achieve maximum transparency.

As there is another research held at Technical University in Košice using epoxy resins, they are chosen for this particular case because of their availability.

Epoxy resin will be infiltrated into lignin-modified samples using OV301 Precision Curing Oven (as it is part of the equipment of robotic laboratory at Faculty of Arts of Technical University in Košice) at a temperature specified by epoxy resin supplier under repeated vacuum and de-vacuum (the complete infiltration should be achieved after about three times the process of vacuum and de-vacuum is performed) [3].

\subsection{Evaluation of obtained samples}

Once the polymer will be infiltrated, the veneer samples will become transparent. At this point, the evaluation process shall begin. Their optical, thermal and mechanical properties will be researched. Optical transmittance and haze will be of interest considering optical properties. Thermal conductivity coefficient will be measured to determine thermal properties of transparent veneer samples. The steady-state technique method will be used to measure it. After consultations with authorities at the faculty, it has been determined that samples will be sent to Slovak Academy of Sciences in order to measure its thermal properties. Strength and modulus will be revealed to set their mechanical properties. For this the samples with the normative shapes are to be created and are to be tested. The samples will be evaluated for compressive strength, tensile strength and bending in all directions to determine their orthotropic properties. The standard according to which the tests are to be undertaken is EN408:2010 to determine its modulus of elasticity in bending, shear modulus, bending strength, modulus of elasticity in tension parallel to the grain, tension strength parallel to the grain, modulus of elasticity in compression parallel to the grain, compression strength parallel to the grain, modulus of elasticity in tension perpendicular to the grain, tension strength perpendicular to the grain, modulus of elasticity in compression perpendicular to the grain, compression strength perpendicular to the grain and shear strength.

\section{Design of transparent wood architectural constructions}

Based on the measured properties, the design of architectural constructions from transparent wood shall follow. The focus will be on façade systems and beams.

\subsection{Façade systems}

Transparent wood will not be suitable for the use on façades in the form of a solid wall, because the thickest achieved sample, so far, has only been of $10 \mathrm{~mm}$ [5]. It is possible to go slightly thicker, but not too much, as transparency in much thicker samples is unachievable, at least, at the current state of technology of production of transparent wood.

If thermal conductivity of transparent wood is considered as $0.17 \mathrm{~W} / \mathrm{mK}$ (a guess based on thermal conductivity of all the components of the composite materials and their respective percentage shares), a solid transparent wood wall would have to be $285 \mathrm{~mm}$ thick to satisfy European standards that will come to be valid after year 2021. As $285 \mathrm{~mm}$ thick transparent 
wood wall is not going to happen, a different approach must be taken. The inspiration might come from double and triple glazing systems with inert gases filled between transparent panes. To create transparent wood façades, an inspiration must be taken from double and triple glazing systems in order to make them valid as a construction material. To make the façade system as transparent as possible, $1.5 \mathrm{~mm}$ thick transparent wood panes should be used. Double pane transparent wood façade with a usual $16 \mathrm{~mm}$ thick layer of argon would have a $\mathrm{U}$ value of $1.1 \mathrm{~W} / \mathrm{m}^{2} \mathrm{~K}$. To satisfy the current standard, $18 \mathrm{~mm}$ thick layer should be used, but to reach the standard after 2021, a $30 \mathrm{~mm}$ thick layer of argon would have to be used. It is different with krypton, as only $17 \mathrm{~mm}$ thick layer would satisfy the standard after 2021. To satisfy the current standard, only $10 \mathrm{~mm}$ thick layer of krypton would be necessary. The usual thickness of krypton layer in glazing systems is $12 \mathrm{~mm}$, which makes TW façade's $\mathrm{U}$ value of $0.82 \mathrm{~W} / \mathrm{m}^{2} \mathrm{~K}$.

Triple pane transparent wood façade with usual $16 \mathrm{~mm}$ thickness of argon layers would have its $\mathrm{U}$ value of $0.55 \mathrm{~W} / \mathrm{m}^{2} \mathrm{~K}$. This is even more efficient than the standard after 2021 requires. To satisfy this standard, only $15 \mathrm{~mm}$ thick layers of argon are necessary. For the current standard it would only be $9 \mathrm{~mm}$ thick layers of argon. With the usual $12 \mathrm{~mm}$ thick layers of krypton in a triple pane transparent wood façade system, the system would have its U value of $0.41 \mathrm{~W} / \mathrm{m}^{2} \mathrm{~K}$. For the satisfaction of the standard valid after 2021 , only $9 \mathrm{~mm}$ thick layers of krypton would be necessary and to satisfy the current standard, only $5 \mathrm{~mm}$ thick layers of krypton would be required. All the options of façade set ups mentioned above are summarized in Table 1 [6].

Table 1: Summary of U values of different transparent wood façade set ups [6].

\begin{tabular}{|c|c|c|c|c|}
\hline \multirow[t]{2}{*}{ Facade type } & \multicolumn{3}{|c|}{ Thickness of layer(s) (mm) } & \multirow[t]{2}{*}{$\mathbf{U}\left(\mathbf{W} / \mathbf{m}^{2} \mathbf{K}\right)$} \\
\hline & Transparent wood & $\mathbf{A r}$ & $\mathbf{K r}$ & \\
\hline \multirow{2}{*}{ Solid wall } & 170 & - & - & 1 \\
\hline & 285 & - & - & 0.6 \\
\hline \multirow{6}{*}{ Double pane } & $2 \times 1.5$ & 16 & - & 1.1 \\
\hline & $2 \times 1.5$ & 18 & - & 0.98 \\
\hline & $2 \times 1.5$ & 30 & - & 0.59 \\
\hline & $2 \times 1.5$ & - & 10 & 0.98 \\
\hline & $2 \times 1.5$ & - & 12 & 0.82 \\
\hline & $2 \times 1.5$ & - & 17 & 0.58 \\
\hline \multirow{6}{*}{ Triple pane } & $3 \times 1.5$ & $2 \times 9$ & - & 0.97 \\
\hline & $3 \times 1.5$ & $2 \times 15$ & - & 0.59 \\
\hline & $3 \times 1.5$ & $2 \times 16$ & - & 0.55 \\
\hline & $3 \times 1.5$ & - & $2 \times 5$ & 0.97 \\
\hline & $3 \times 1.5$ & - & $2 \times 9$ & 0.55 \\
\hline & $3 \times 1.5$ & - & $2 \times 12$ & 0.41 \\
\hline \multicolumn{5}{|c|}{$\begin{array}{l}\text { satisfies current EN standard } \\
\text { satisfies EN standard after } 2021\end{array}$} \\
\hline
\end{tabular}

Having an actual thermal conductivity value of transparent veneers might lead into different conclusions, but if it were remotely close to a predicted value, it might lead to a considerable 
savings of material, as transparent wood layer could be thinner than glass and inert gasses could be used in shorter spans, therefore would be of lower volumes compared to standard glazing systems.

In a Physibel software, critical details of construction will be evaluated and final design will adapt to conclusions produced by the program. Various façade set ups might emerge during the process.

\subsection{Beams}

To achieve the best results, the thinnest possible elements must be incorporated into the design of beams made of transparent wood. There are few ways to achieve this. Composite cross-section beams are the most obvious solution. Firstly, "I" beams will be designed, where the web of those beams is to be made of thin transparent wood and flanges are to be made either of a laminated veneer lumber or thick transparent wood members. To achieve a better mechanical properties, the member might also be created by lamination as transparent plywood [7]. This is the lightest possible version of transparent wood beams in the means of appearance. Architectonically, a structure made using such beams would almost seem to be floating or levitating in space, which might become much desired (Figure 1) [8].

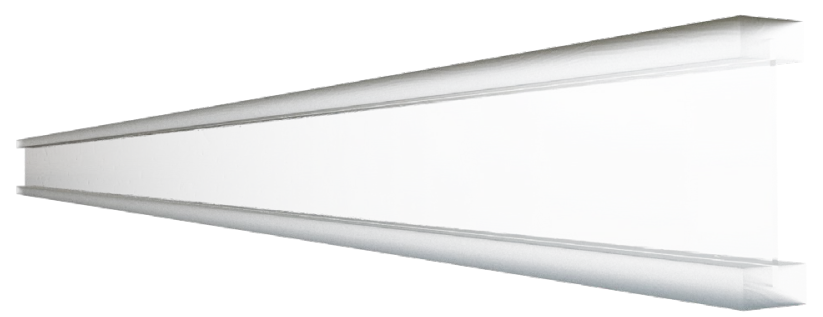

Figure 1: Transparent wood I beam rendering [8] Another option is to create box beams. They would be created in a similar fashion as "I" beams. Flanges could again be made of laminated veneer lumber or thick transparent wood members and webs would be made of thin transparent wood panels. Again, transparent

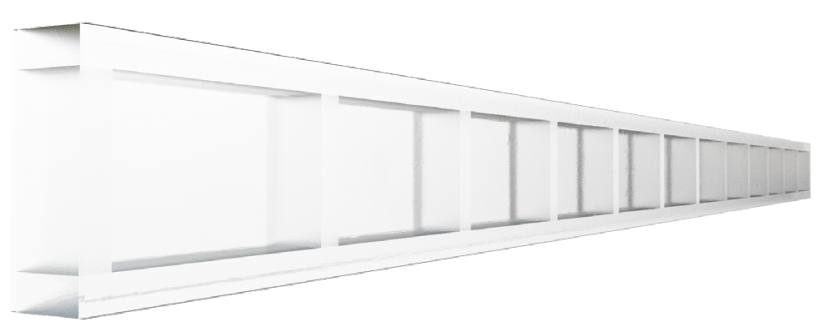

Figure 2: Transparent wood Vierendeel box beam rendering [8] plywood can be used. These beams are not as light (although still pretty light), but can support bigger weights. The variation of the box beams is to create a Vierendeel truss (again, either by using natural or thick transparent wood) and add a thin transparent wood panels at its both sides (Figure 2). Out of all the mentioned it is a least light variant, but the firmest [8].

Transparent wood trusses are yet another way to use transparent wood structurally (Figure 3). Of course, the thicker members will have to be used to create them, but not as thick, as it would require a single massive beam. So, compared to that, it is still a lighter structure. Such trusses can be all transparent wood, or only a flange would be made of transparent wood and it would then work together with steel cable to

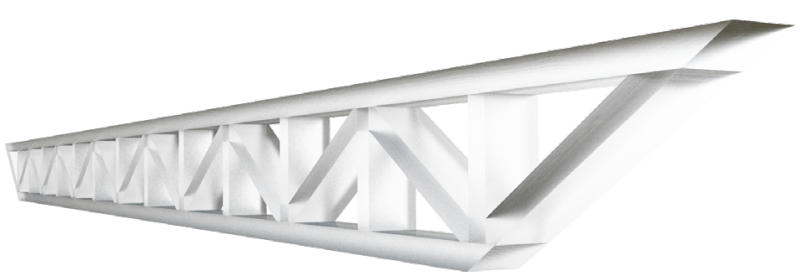

Figure 3: Transparent wood truss rendering [8] 
achieve a much lighter structure overall [8].

As mentioned before, massive transparent wood beams are not possible to create, because transparency cannot be achieved in very thick samples. However, there might be a chance to create massive beams inspired by parallam structures. Parallams are created using wood stands. They are of a scale that can be turned transparent. Strands would then be bonded by the same polymer which is used in the infiltration process of polymer into lignin-modified wood. This way, even massive transparent wood beams might see the light of day.

The designs will be evaluated in software for structural analysis available at the university and modified according to the obtained results to achieve the best performance.

\section{Building and testing scaled models}

Once designed, façades and beams shall be built in scale, as there is not a technology at the university to create the full scale models. After, they will be tested experimentally, whether their properties match those obtained during the software analysis.

The great challenge, considering transparent wood façades will be to secure inert gasses to not leak from the construction, because it is yet unclear, whether transparent wood is not too porous for such construction. If it is, some other way will have to be thought of to make transparent wood façades possible or first, to create delignified samples for the façades and test the leakage. In the case leakage would not be a problem, critical details will be tested in climatic chamber and/or in situ.

Beams in scale will be evaluated in the VUKONZE laboratories at Technical University in Košice and their mechanical properties shall be put to the test.

\section{Conclusion}

Transparent wood is still a very new material with properties that have still not been fully researched. The research of its applications in architectural constructions has never been done before, but its properties and appearance predetermine it for such use. This is why this research is to be undertaken at Technical University in Košice in the near future. The research shall be done methodologically as described in this article focused on façade and beam constructions. Its results will then be reviewed and published.

\section{Acknowledgements}

This contribution is supported by the Scientific Grant Agency and project KEGA 046TUKE-4/2019 supported by the Cultural Grant Agency of the Ministry of Education, Science, Research and Sport of the Slovak Republic and the Slovak Academy of Sciences. This paper was elaborated with financial support project with ITMS code: 26220220182 (TECHNICOM).

\section{References}

[1] Fink, S. (2009). Transparent Wood - A New Approach in the Functional Study of Wood Structure. Holzforschung - International Journal of the Biology, Chemistry, Physics and Technology of Wood, 46(5), pp. 403-408.

[2] Yuanyuan Li, Qiliang Fu, Shun Yu, Min Yan, and Lars Berglund, Optically Transparent Wood from a 
Nanoporous Cellulosic Template: Combining Functional and Structural Performance, Biomacromolecules 201617 (4), 1358-1364,

[3] Mingwei Zhu, Jianwei Song, Tian Li, Amy Gong, Yanbin Wang, Jiaqi Dai, Yonggang Yao, Wei Luo, Doug Henderson, Liangbing $\mathrm{Hu}$ (2016), Highly anisotropic, highly transparent wood composites. Advanced Materials, 28(26), 5181-5187

[4] Li, Y., Fu, Q., Rojas, R., Yan, M., Lawoko, M., \& Berglund, L. (2017). A new perspective on transparent wood: Lignin-retaining transparent wood. ChemSusChem.

[5] Li, Y., Yang, X., Fu, Q., Rojas, R., Yan, M., \& Berglund, L. (2018). Towards centimeter thick transparent wood through interface manipulation. Journal of Materials Chemistry A, 6(3), 1094-1101.

[6] Karl'a, V., (2019) Update of Research on Transparent Wood, YS2019 - Young Scientist 2019: proceedings of the 11th International Scientific Conference of Civil and Environmental Engineering for PhD. Students and Young Scientists. - Bristol (UK): IOP Publishing p. 1-8 [online]. - ISSN 1757-8981.

[7] Fu, Q., Yan, M., Jungstedt, E., Yang, X., Li, Y., \& Berglund, L. A. (2018). Transparent plywood as a load-bearing and luminescent biocomposite. Composites Science and Technology.

[8] Katunský, D., Kanócz, J., Karl'a, V., (2018) Structural Elements with Transparent Wood in Architecture, International Review of Applied Sciences and Engineering = IRASE. - Budapest (Hungary): Akadémiai Kiadó Roč. 9, č. 2 (2018), s. 101-106 [print]. - ISSN 2062-0810 